\title{
Detrimental Views on Perceived Risks and their Influence on Travel Decisions
}

Jose K Antony ${ }^{*}$ and Joby Thomas ${ }^{\dagger}$

\begin{abstract}
This study, therefore, proposes to identify and investigate the risk perception dimensions of tourists travelling from South India and to determine the influence that these dimensions can have on tourist behaviour. The primary data was gathered through a survey, involving a scheduled questionnaire. Based on the nature of the data collected, data analysis techniques such as Cross Tabulation, Independent Sample t-Test and One-way ANOVA Test were employed to identify characters of heterogeneity among tourist groups based on the risk perception dimensions.
\end{abstract}

Keywords: Perceived risks, Perceived risk dimensions, Travel decisions, Travel decision making

\section{Introduction}

Though Travel is an exciting phenomenon in the world today (Cohen, 1995), making travel decisions is never an easy task as tourists have to take many decisions involving numerous factors such as time, finance, transportation, destinations, and activities. Perceived risks relating to these factors have been widely employed in the studies relating to the field on Travel Behavior (Yavas, 1987;

*Christ University, Bengaluru, India; jose.antony@christuniversity.in

† Christ University, Bengaluru, India; joby.thomas@christuniversity.in 
Verghage, Yavas \& Green, 1990; Lepp \& Gibson, 2003) and these studies in the tourism context have been beneficial to both the tourists and the marketers, in understanding the decisions and choice of destinations by travelers.

The studies on risk perception of travellers gain importance because of the intangible nature of the services that are involved in tourism and because these services have to be simultaneously consumed as they are produced (Zeithaml, 1981). The intangible nature of services makes these services vary in their quality. Therefore, there is always a very high element of risk associated with the purchase and consumption of services; mainly because it is very difficult to evaluate services before the experience.

The study investigated the influence of the prominent dimensions of perceived risks on the decision-making behavior of consumers. Through intense literature reviews, numerous dimensions of perceived risk were identified. These prominent dimensions of perceived risks were then evaluated on their significance in the decision-makingbehaviour of travellers.

\section{Review of Literature}

Perceived risk was defined as a level of uncertainty that consumers could face when they were not able to foresee the after-effects of their purchase decisions (Schiffman \& Kanuk, 2000). The dimensions of uncertainty and outcome as relevant dimensions of perceived risks were highlighted through this definition. Another study offered three different views addressing the confusion around the explanations on risk, namely that the risk construct is made up of several individual risk elements, the risk may involve several different and distinct elements, and the risk elements may unfold in many different ways during different situations and events (Yates \& Stone, 1992).

Five important dimensions of risk perceptions, namely financial, psychological, performance, physical and social dimensions were identified in a study that first operationalised the construct of perceived risk (Jacoby \& Kaplan, 1972). Numerous other studies were also instrumental in analyzing and studying numerous risk 
perception dimensions as one of the most significant and powerful factors in understanding and explaining the behavior of travel consumers (Brooker, 1984; Kaplan \& Jacoby, 1972; McDougall \& Yang, 2004; Greatorex \& Mitchell, 1990; Ryan \& Peter, 1976; and Gronhaug \& Stone, 1993; Antony, 2016).

A most recent study identified the prominent dimensions of perceived risks among tourists from South India (Antony, 2016). According to the study, tourists perceived maximum risk when it involved their safety and health during travel. Tourists looked forward to experiencing anything new during holidays, with learning and involvement forming an integral part of their holiday experience.

A comprehensive analysis of risk perception with relation to the character of tourists was identified for the first time (Moutinho, 2000). The study identified perceived the risk to be a combination of consequences and uncertainties, and this understanding was found to be more generalised than any other definitions that had been already studied and discussed. Uncertainties about the product, the place, the modes of purchase, uncertainties arising out of the financial and psychosocial consequences, and the subjective uncertainties that could be encountered by the tourists were the four significant factors that were proposed in the study. The study also examined the relationships between the elements of risk perceptions to more clearly understand the tourists' perception of risk involved in travel purchase decisions.

The decision making process of the consumer incorporated rules that employed several different choices, which ultimately resulted in the selection of the best alternative (Crompton, 1992; Crompton \& Ankomah, 1993; Van Raaij \& Crotts, 1994; Ankomah et al., 1996). The most significant of the studies involved a set of propositions that were based on a so-called consideration set, which ultimately resulted in the final choice decision to be developed (Crompton \& Ankomah, 1993) and this study later motivated other researchers to expand their studies on travel decision making. Another important study found that the choice of a single destination resulted in travellers not making any elaborate plans or arrangements for their trips (Lindh, 1998). The study proved that in the absence of 
alternative travel destinations, three important travel decision stages namely decisions on whether to travel, the destination to which to travel to and how to travel there were not completely processed in the tourists' minds. It was at this juncture that factors such as the travellers' personal attributes, earlier experiences and perception of risks could influence the stages of decision making during travel.

Decision making before and during travel is highly a unique process as there is a huge amount of intangibility on the returns of travel purchase decisions over a long period of time (Moutinho, 1987). The experiential characteristics of the tourism products that did not offer any form of intangible results, substantial expenses incurred on the tourism products, careful planning before the actual travel purchase and the actual visitation to the destination were four exquisite forms of travel purchase decisions (Mathieson $\&$ Wall, 1982). The concept of intangibility was further reiterated in a study that defined the differences while decision making between purchasing tangible goods and services like travel (Hudson \& Gilbert, 2000).

For the first time, a model that emphasized on the challenges, valuation of travel risk perception and their influence on decision making was proposed (Schmoll, 1977). The model included four specifications, namely the stimuli to travel, the external factors that could influence travel, personal and social factors that could influence travel behaviour, and the character of the tourist destination. The model was successful to an extent in identifying the factors involved in the travel purchase decision process. However, the difficulty in quantifying the relevancy of the factors and analyzing the interrelationships between the factors turned out to be one of the important drawbacks of the model.

While studying the correlation between travel purchase decisions and risk perception, three major causes as the primary forces of risk perception were ascertained to influence foreign travel decisions (Yavas, 1987). These were the services and products, with the fundamental differences of intangibility, the high involvement situations arising from the travel to the foreign destinations and the risk perception that could influence the travellers' decisions. The 
differences in intangibility were notable as this factor resulted in the inability to correctly infer the benefits from the travel, which most commonly resulted in anxiety during travel. Travel consumption behaviour decisions such as the style of travel and the likelihood of travel were influenced and altered by the power of perceived risks (Sonmez \& Graefe, 1998).

Studies also identified newer dimensions and forms of risk perceptions that could have an influence on travel decisions, most notable among them being the studies conducted on pleasure travel (Roehl \& Fesenmaier, 1992) as well as the studies on international leisure travel (Lepp \& Gibson, 2003). Familiarity with the travel and the destination could influence the risk perception of travellers (Cheron \& Ritchie, 1982), and another study found the influence of language on travel decisions making (Pinhey \& Iverson, 1994). The differences in language also influenced the tourists' choices of holiday destinations (Yavas, 1987).

\section{Research Gap and Objective of the Study}

Prominent studies have already been carried out on the impact of perceived risks on travellers, most recently being the study on identifying the prominent dimensions of perceived risks among tourists in South India (Antony, 2016). However, the number of research studies performed on the influence of the risk dimensions in travel decision making was limited. The present study, therefore, aims to carry forward the findings from the earlier study (Antony, 2016) by evaluating the relationship between the identified risk perception dimensions of tourists from South India and travel decision making.

\section{Sample Size}

The investigation covered the metro cities in South India, namely Visakhapatnam in Telangana State, Hyderabad in Andhra, Bengaluru in Karnataka, Chennai in Tamil Nadu and Kochi in Kerala. The sample size for the survey was around 500 respondents, and the respondents were selected using Random Sampling Technique. 


\section{Data Collection Sources and Methods}

The secondary data required for the study was derived from academic books, printed materials, newspapers, magazines, journals, articles, websites and related research articles, while the primary data was collected from the population and the sample group under the area of investigation.

Data was collected with the help of a scheduled questionnaire that was designed based on the objectives of the study andwas circulated among the respondents. The questionnaire included the respondents' demographic information, their travel information, experiences and perception of risks that they might encounter during their travel and holiday at the destination. Multiple choices, open-ended and rating using the Likert Five Point Rating Scale were used in the Questionnaire to elicit the required information. Statistical tools and techniques were then used to analyze the data from the questionnaire.

\section{Findings with the support of Group Statistics}

6.1 To analyse whether there was a significant relationship between Age Group and always starting a holiday without medicines and first aid

Table 1: One-way ANOVA Test between Age Group and always starting a holiday without medicines and first aid

\begin{tabular}{|c|c|c|c|c|c|}
\hline & $\begin{array}{l}\text { Sum of } \\
\text { Squares }\end{array}$ & Df & $\begin{array}{c}\text { Mean } \\
\text { Square }\end{array}$ & $\mathrm{F}$ & Sig. \\
\hline Between Groups & 65.965 & 4 & 16.491 & 9.290 & 0.000 \\
\hline Within Groups & 878.707 & 495 & 1.775 & & \\
\hline Total & 944.672 & 499 & & & \\
\hline
\end{tabular}

The ANOVA Table lists the Mean, Standard Deviation and Individual Sample Sizes of the importance for tourists to always carry their medicines and first aid during a holiday. The significance level of 0.000 is lower than the threshold value of 0.05 indicating that there is a significant relationship between respondents' age groups and starting a holiday without medicines and first aid. 
With the support of cross tabulation, it is further proved that there is a significant relationship between respondents' age groups and starting a holiday without medicines and first aid.

Table 2: Age - Never leave for a holiday without medicines and first aid Cross Tabulation

\begin{tabular}{|c|c|c|c|c|c|c|c|c|}
\hline & & \multicolumn{5}{|c|}{$\begin{array}{l}\text { Never leave for a holiday without medicines } \\
\text { and first aid }\end{array}$} & \multirow[t]{2}{*}{ Total } \\
\hline & & & $\begin{array}{l}\text { Strongly } \\
\text { Disagree }\end{array}$ & Disagree & Neutral & Agree & $\begin{array}{l}\text { Strongly } \\
\text { Agree }\end{array}$ & \\
\hline \multirow{5}{*}{$\begin{array}{l}\text { Age } \\
\text { (in } \\
\text { years) }\end{array}$} & $\begin{array}{l}16 \\
25\end{array}$ & - & 9 & 17 & 10 & 17 & 43 & 96 \\
\hline & $\begin{array}{l}26 \\
35\end{array}$ & - & 10 & 48 & 27 & 6 & 27 & 118 \\
\hline & $\begin{array}{l}36 \\
45\end{array}$ & - & 5 & 37 & 27 & 14 & 20 & 103 \\
\hline & & - & 12 & 35 & 19 & 10 & 16 & 92 \\
\hline & $\begin{array}{l}\mathrm{Ab} \\
56\end{array}$ & & 10 & 13 & 13 & 19 & 36 & 91 \\
\hline Total & & & 46 & 150 & 96 & 66 & 142 & 500 \\
\hline
\end{tabular}

Of the 500 respondents, it was found that the respondent pool was clearly divided over the fact that they never left for a holiday without carrying their medicines and first aid. While many respondents were neutral in their stand, a good number of respondents above the age of 26 and below the age of 56 disagreed that they would never leave for a holiday without their medicines and first aid.

6.2 To analyse whether there was a significant relationship between Anxiety about safety and security as a perceived risk factor and Gender.

Table 3: Mean Score between Anxiety about safety and security and Gender

\begin{tabular}{lllllr}
\hline & Gender & $\mathrm{N}$ & Mean & $\begin{array}{c}\text { Std. } \\
\text { Deviation }\end{array}$ \\
\hline $\begin{array}{l}\text { Anxiety about safety and } \\
\text { security always prevents from } \\
\text { taking risks during travel }\end{array}$ & Male & 120 & 3.28 & 1.055 \\
\hline
\end{tabular}


Table 4: Independent Sample t-Test between Anxiety about safety and security and Gender

\begin{tabular}{|c|c|c|c|c|c|c|c|c|}
\hline & \multicolumn{7}{|c|}{ t-test for Equality of Means } \\
\hline & & \multirow[t]{2}{*}{$\mathrm{T}$} & \multirow[t]{2}{*}{$\mathrm{df}$} & \multirow[t]{2}{*}{$\begin{array}{c}\text { Sig. } \\
\text { (2-tailed) }\end{array}$} & \multirow[t]{2}{*}{$\begin{array}{l}\text { Mean } \\
\text { Difference }\end{array}$} & \multirow[t]{2}{*}{$\begin{array}{c}\text { Std. } \\
\text { Error } \\
\text { Difference }\end{array}$} & \multicolumn{2}{|c|}{$\begin{array}{l}95 \% \text { Confidence } \\
\text { Interval of the } \\
\text { Difference }\end{array}$} \\
\hline & & & & & & & Lower & Upper \\
\hline $\begin{array}{l}\text { Anxiety } \\
\text { about } \\
\text { safety and }\end{array}$ & $\begin{array}{l}\text { Equal } \\
\text { variances } \\
\text { assumed }\end{array}$ & 2.505 & 498 & 0.013 & 0.268 & 0.107 & 0.058 & 0.477 \\
\hline $\begin{array}{l}\text { prevents } \\
\text { from } \\
\text { taking } \\
\text { risks } \\
\text { during } \\
\text { travel }\end{array}$ & $\begin{array}{l}\text { Equal } \\
\text { variances } \\
\text { not } \\
\text { assumed }\end{array}$ & 2.448 & 192.688 & 0.015 & 0.268 & 0.109 & 0.052 & 0.483 \\
\hline
\end{tabular}

Between subjects, $\mathrm{t}$-Test was conducted to determine the effect of Anxiety on safety and security that always prevented tourists from taking risks during travel and Gender. Using a 2 tailed .05 criteria, it was found that the Mean and Standard Deviation Score for female respondents (M: 3.28; SD: 1.055) is higher than the Mean and Standard Deviation Score for male respondents (M: 3.02; SD: 1.009), $t(498)=2.505, p=0.013$, which is lesser than 0.05. Therefore, there is a significant relationship between anxiety about safety and security as a perceived risk factor and gender.

The mean female anxiety aboutsafety and security shows that it always prevented women from taking risks during travel and the mean male anxiety aboutsafety and security shows that concerns about safety and security do not have a large role in preventing men from taking risks during travel.

6.3 To analyze whether there was a significant relationship between Educational Qualifications and interest in reading and studying the culture of the destination that the tourist plan to visit 
Table 5: One-way ANOVA Test between Educational Qualifications and Interest in reading and studying the culture of the destination

\begin{tabular}{lrrrrr}
\hline & Sum of Squares & df & $\begin{array}{c}\text { Mean } \\
\text { Square }\end{array}$ & F & Sig. \\
\hline Between Groups & 10.848 & 3 & 3.616 & 3.361 & 0.019 \\
Within Groups & 533.680 & 496 & 1.076 & & \\
Total & 544.528 & 499 & & & \\
\hline
\end{tabular}

The ANOVA Table lists the Mean, Standard Deviation and Individual Sample Sizes of the interest in reading and studying the culture of the destination that the tourist plan to visit. The significance level of 0.019 is less than the threshold value of 0.05 indicating that there is a significant relationship between educational qualifications and interest in reading and studying about the culture of the destination that the tourist plan to visit.

With the support of cross tabulation, it is further proved there is a significant relationship between Educational Qualifications and interest in reading and studying the culture of the destination that the tourist plans to visit.

Table 6 : Educational Qualification - Read and study the destination Cross Tabulation

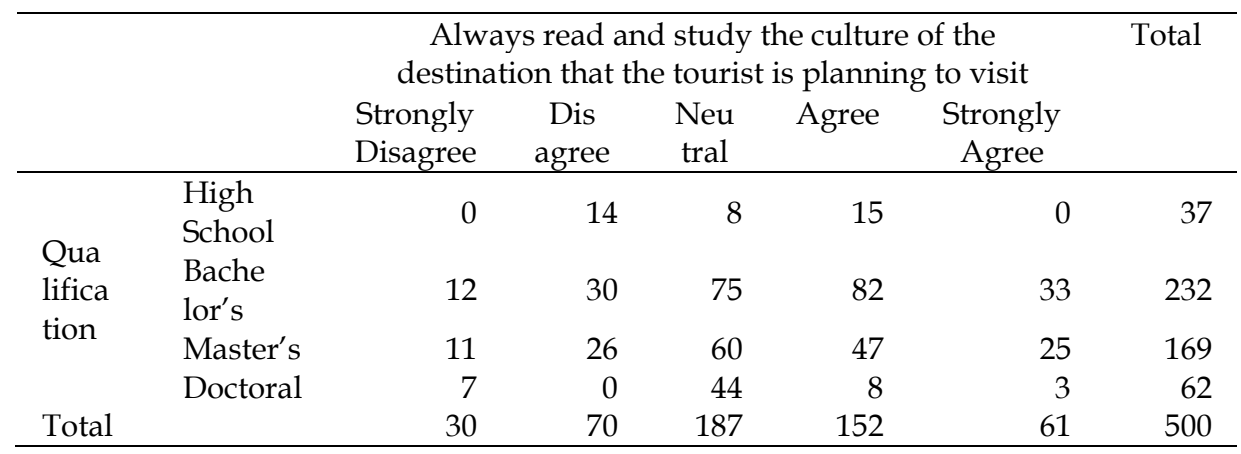

Of the 500 respondents, 213 agreed that they always read and study the culture of the destination that they planned to visit. Majority of the respondents had a Bachelor's degree and, of them, 82 agreed that they always read and studied the culture of the destination that they planned to visit. Also, 15 of the 37 respondents with High 
School degree agreed that they always read and studied the culture of the destination that they planned to visit. However, 60 of the 169 respondents with Master's degree and 44 of the 62 respondents with Doctoral degree adopted a neutral stand, that they sometimes read and study, and sometimes do not read and study the culture of the destination that they planned to visit.

\subsection{To analyze whether there was a significant relationship between Annual Income and the comfort level with the holiday destination that the tourists choose}

Table 7: One-way ANOVA Test between Annual Income and Comfort level with the holiday destination that the tourists choose

\begin{tabular}{lrrrrr}
\hline & Sum of Squares & df & Mean Square & F & Sig. \\
\hline Between Groups & 21.664 & 4 & 5.416 & 4.942 & 0.001 \\
Within Groups & 542.438 & 495 & 1.096 & & \\
Total & 564.102 & 499 & & & \\
\hline
\end{tabular}

The ANOVA Table lists the Mean, Standard Deviation and Individual Sample Sizes of the comfort level with the holiday destination that the tourists choose. The significance level of 0.001 is lesser than the threshold value of 0.05 indicating that there is a significant relationship between annual income and the tourists' expectation of a comfort level with the holiday destination.

With the support of cross tabulation, it is further proved there is a significant relationship between Annual Income and the comfort level with the holiday destination that the tourists choose.

Of the 500 respondents, majority of the respondents took a neutral stand that they may or may not focus on their comfort with the holiday destination that is chosen. Irrespective of their annual income, all respondents wished for more comfort in the holiday destinations they chose to visit, the investigation found that as the income of the respondents increased, so did their need for more comfort with the holiday destination they chose. Respondents with an annual income above Rs.7,50,000 were more inclined towards selecting a destination that they felt would offer them the most comfort, and at the same time, respondents with an annual income 
Table 8: Annual Income - Always make sure of comfort with the holiday destination that is chosen Cross Tabulation

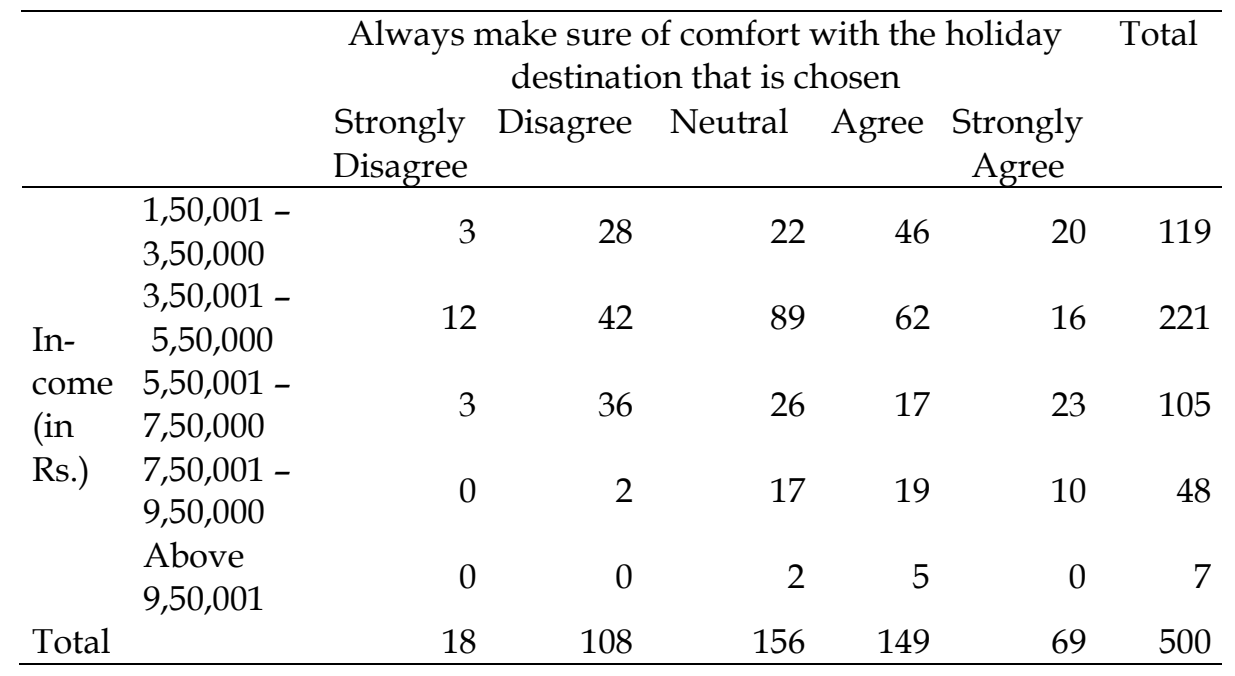

between Ks.1,bU,UUI and Ks.b, $\mathrm{bU}, \mathrm{UUU}$ were clearly divided over the comfort of the destination they chose.

6.5 To analyze whether there was a significant relationship between Employment Status and the importance of using telecommunication devices during a holiday

Table 9: One-way ANOVA Test between Employment Status and the importance of using telecommunication devices during a holiday

\begin{tabular}{lrrrrc}
\hline & Sum of Squares & df & Mean Square & F & Sig. \\
\hline $\begin{array}{l}\text { Between } \\
\text { Groups }\end{array}$ & 18.170 & 4 & 4.543 & 3.868 & 0.004 \\
Within & & & & & \\
$\begin{array}{l}\text { Groups } \\
\text { Total }\end{array}$ & 581.372 & 495 & 1.174 & & \\
\hline
\end{tabular}

The ANOVA Table lists the Mean, Standard Deviation and Individual Sample Sizes of the importance for tourists to use telecommunication devices during a holiday. The significance level of 0.004 is lower than the threshold value of 0.05 indicating that there is a significant relationship between employment status and the importance of using telecommunication devices during a holiday. 
With the support of Cross Tabulation, it is further proved that there is a significant relationship between Employment Status and the importance of using telecommunication devices during a holiday.

Table 10: Employment Status - Always carry and use a smartphone during a holiday Cross Tabulation

\begin{tabular}{llrrrrrr}
\hline & \multicolumn{6}{c}{ Always carry and use a smartphone during } & Total \\
& & \multicolumn{7}{c}{$\begin{array}{c}\text { a holiday } \\
\text { Strongly } \\
\text { Disagree }\end{array}$} & $\begin{array}{c}\text { Dis } \\
\text { agree }\end{array}$ & Neutral & Agree & Strongly \\
Agree & \\
\hline \multirow{5}{*}{$\begin{array}{l}\text { Employ } \\
\text { ment }\end{array}$} & $\begin{array}{l}\text { Students } \\
\text { Professio }\end{array}$ & 1 & 14 & 20 & 25 & 21 & 81 \\
& $\begin{array}{l}\text { nals } \\
\text { Self }\end{array}$ & 26 & 17 & 48 & 80 & 42 & 213 \\
& Employed & 17 & 12 & 26 & 40 & 26 & 121 \\
& Retired & 0 & 7 & 21 & 9 & 3 & 40 \\
Total & Others & 1 & 3 & 11 & 22 & 8 & 45 \\
& & 45 & 53 & 126 & 176 & 100 & 500 \\
\hline
\end{tabular}

Majority of the respondents, in all employment categories, agreed that it was important for them to use various forms of telecommunication devices during a holiday, thereby reducing the Communication Risk during the holiday.

Of the 81 students, 46 respondents answered that they always carried and used their smartphones during a holiday. Of the 213 professionals, 122 of them answered that they always carried and used their smartphones during a holiday. Of the 121 self-employed respondents, 66 respondents always used their smartphones during a holiday. When it came to the retired persons, 21 of the 40 respondents answered neutrally. There was a small group of respondents, 98 to be exact, who were of the opinion that they need not always carry and use their smartphones during a holiday. Of them, 43 were professionals, and 29 were self-employed.

6.6 To analyze whether there was a significant relationship between Employment Status and Choice of a packaged tour 
Table 11: One-way ANOVA Test between Employment Status and Choice of a packaged tour

\begin{tabular}{lrrrcc}
\hline & Sum of Squares & df & Mean Square & F & Sig. \\
\hline Between & 1.548 & 4 & 0.387 & 0.666 & 0.616 \\
Groups & & & & & \\
Within & 287.820 & 495 & 0.581 & & \\
Groups & 289.368 & 499 & & & \\
Total & & & & & \\
\hline
\end{tabular}

The ANOVA Table lists the Mean, Standard Deviation and Individual Sample Sizes of the choice of a packaged tour. The significance level of 0.616 is higher than the threshold value of 0.05 indicating that there is no significant relationship between Employment Status and choice of a packaged tour

6.7 To analyze whether there was a significant relationship between the Choice of Package Tour and Tourists Experiencing something totally new from what they have already experienced before

Table 12: One-way ANOVA Test between Choice of a Tour Package and New Experience

\begin{tabular}{lrrrrr}
\hline & $\begin{array}{c}\text { Sum of } \\
\text { Squares }\end{array}$ & df & $\begin{array}{c}\text { Mean } \\
\text { Square }\end{array}$ & F & Sig. \\
\hline Between Groups & 7.986 & 4 & 1.997 & 3.512 & 0.008 \\
Within Groups & 281.382 & 495 & 0.568 & & \\
Total & 289.368 & 499 & & & \\
\hline
\end{tabular}

The ANOVA Table lists the Mean, Standard Deviation and Individual Sample Sizes of experiencing something totally new from tour packages and the tourists experiencing something totally new from what they have already experienced before.

The significance level of 0.008 is less than the threshold value of 0.05 indicating that there is a significant relationship between choice of package tour and towards experiencing something totally new from what they have already experienced before.

With the support of cross tabulation, it is further proved that there is a significant relationship between choice of package tour and 
tourists experiencing something totally new from what they have already experienced before.

Table 13: Type of tour - Experiencing something totally new Cross Tabulation

Ideal holiday involves experiencing something totally new Total from what has already been experienced before

Strongly Disagree Neutral Agree Strongly Agree Disagree

\begin{tabular}{|c|c|c|c|c|c|c|c|}
\hline & $\begin{array}{l}\text { Fully } \\
\text { Packaged }\end{array}$ & 18 & 16 & 36 & 101 & 68 & 239 \\
\hline $\begin{array}{l}\text { Type } \\
\text { of tour }\end{array}$ & $\begin{array}{l}\text { Non- } \\
\text { packaged }\end{array}$ & 38 & 33 & 25 & 35 & 37 & 168 \\
\hline & $\begin{array}{l}\text { Partially } \\
\text { packaged }\end{array}$ & 6 & 6 & 16 & 25 & 40 & 93 \\
\hline Total & & 62 & 55 & 77 & 161 & 145 & 500 \\
\hline
\end{tabular}

A category-wise study of it indicates that 101 respondents have agreed and 68 respondents have strongly agreed that a fully packaged tour would provide the ideal holiday that would enable them in experiencing something totally new from what they have already experienced before. While 168 respondents preferred a non-packaged tour, only 93 respondents preferred a partially packaged tour.

\section{Suggestions and Conclusion}

The study was able to develop an understanding of the dimensions of perceived risk and their influence on travel decision making. As the tourists from South India emphasised the need for safety and sound health during travel, Travel Professionals were required to orient tourists about personal safety and carrying medicines and first aid with them whenever they travelled to a holiday destination.

Travel Professionals should share the maximum amount of information on the destination and travel with the tourists. They should also motivate the tourists to read and learn about the destinations they plan to visit in order to reduce their perception of risk before and during travel. 
Tourists are to be encouraged to use telecommunications devices during travel as this helps reduce the perceived communication risks. Travel Professionals may orient tourists on the available Information and Communication Technologies that they can readily use, to gather information and acquaint themselves with the travel.

Travel Professionals are to be aware that irrespective of their annual income, all tourists wish for more comfort in the holiday destinations they chose to visit. Most of the time, as the income of the tourists' increase, so do their need for more comfort with the holiday destination they choose to visit.

Travel Professionals need to understand that Tourists most often prefer packaged tours, for which the tourists approach them. This is because no matter how much the tourists would know about a destination, tourists still believe that package tours will be able to provide them with an ideal holiday that would enable them in experiencing something totally new from what have already experienced before. This makes the role of Travel Professionals even more significant.

Every individual, irrespective of the nature of their employment takes a holiday from time to time as it helps them to unwind. Therefore, it is essential that Travel Professionals should be ready to cater to the needs of all categories of tourists and provide them with a relaxing, unique, and different environment at the destination.

\section{Scope for Further Research}

The study mainly focused on the risk perception of tourists travelling from the metro cities of South India. Had the study focused on tourists travelling from other cities in India, the results may have been different, and other dimensions of risk perception may have been identified.

An increased number of demographic and psychographic variables can also be included in future research to obtain a clearer picture of the factors associated with risk perception dimensions that could 
influence travel decision making. A more elaborate study could also lead to the development of a conceptual model on the same.

The study was more general in that it did not distinguish and find the difference in risk perception among business and leisure travellers.

\section{References}

Alba, J. W., \& Hutchinson, J. W. (1987). Dimensions of Consumer Expertise. Journal of Consumer Research, 13, 411-454.

Ankomah, P. K., Crompton, J., \& Baker, D. (1996). Influence of cognitive distance in vacation choice. Annals of Tourism Research, 23(1), 138-150.

Antony, J. K. (2016). Perceived Risks; Prominent Dimensions among Tourists from South India. Atna-Journal of Tourism Studies, 11(2), 61-79.

Barker, M., Page, S., \& Meyer, D. (2003). Urban visitor perceptions of safety during a special event. Journal of Travel Research, 41(4), 345-355.

Bauer, R. (1967). Consumer behavior as risk taking. In D. Cox (Ed.), Risk taking and information handling in consumer behavior (pp. 23 - 33). Cambridge: Harvard University Press.

Brooker, G. (1984). An assessment of an expanded measure of perceived risk. Advances in Consumer Research, 11, 439-441.

Chandler, J. A., \& Costello, C. A. (2002). A Profile of Visitors at Heritage Tourism Destinations in East Tennessee according to Plog's Lifestyle and Activity Level Preferences Model. Journal of Travel Research, 41, 161-166.

Cohen, E., \& Cooper, R. L. (1986). Language and Tourism. Annals of Tourism Research, 13, 533-563.

Coshall, J. T. (2003). The Threat of Terrorism as an Intervention on International Travel Flows. Journal of Travel Research, 42, 4-12.

Dolnicar, S. (2005). Understanding Barriers to Leisure Travel: Tourist Fears as a Marketing basis. Journal of Vacation Marketing, 11(3), 197208.

Dowling, G. R., \& Staelin, R. (1994). A Model of Perceived Risk and Intended Risk-handling Activity. Journal of Consumer Research, 21, 119134.

Fletcher, J., \& Morakabati, Y. (2008). Tourism Activity, Terrorism and Political Instability within the Commonwealth: The Cases of Fiji and Kenya. International Journal of Tourism Research, 10(6), 537-556. 
Hofstede, G. (1983). The Cultural Relativity of Organizational Practices and Theories. Journal of International Business Studies, 14(2), 75-89.

Hofstede, G. (1984). Culture's consequences: International Differences in WorkRelated Values. Beverly Hills, California: Sage Publications, Inc.

Hofstede, G. (2001). Culture's consequences: Comparing values, behaviors, institutions, and organizations across nations. California: Sage Publications.

Jacoby, J., \& Kaplan, L. (1972). The components of risk perception. In M. Venkatesan (Ed.), Proceedings of the 3rd annual conference (pp. 382-393). Champaign: Association for Consumer Research.

Kaplan, L., Szybillo, G., \& Jacoby, J. (1974). Components of Perceived Risk in Product Purchase: A Cross-validation. Journal of Applied Psychology, 59(3), 287-291.

Kozak, M., Crotts, J., \& Law, R. (2007). The Impact of Perception of Risk on International Travellers. International Journal of Tourism Research, 9(4), 233-242.

Laroche, M., McDougall, G. H. G., Bergeron, J., \& Yang, Z. (2004). Exploring How Intangibility Affects Perceived Risk. Journal of Service Research, 6(4), 373-389.

Lepp, A., \& Gibson, H. (2003). Tourist roles, perceived risk and International Tourism. Annals of Tourism Research, 30(3), 606-624.

Mitra, K., Reiss, C., \& Capella, L. (1999). An Examination of perceived risk, Information search and behavioral intentions in search, experience and credence services. Journal of Services Marketing, 13(3), 208-226.

Mazursky, D. (1989). Past Experience and Future Tourism Decisions. Annals of Tourism Research, 16, 333-344.

Mitchell, V.-W., Davies, F., Moutinho, L., \& Vassos, V. (1999). Using Neural Networks to Understand Service Risk in the Holiday Product. Journal of Business Research, 46, 167-180.

Mitra, K., Reiss, M. C., \& Capella, L. M. (1999). An Examination of Perceived risk, information search and behavioral intentions in search, experience and credence services. Journal of Services Marketing, 13(3), 208.

Moutinho, L. (1987). Consumer behavior in tourism. European Journal of Marketing, 21(10), 05-44.

Nickerson, N. P., \& Ellis, G., D. (1991). Traveler Types and Activation Theory: A Comparison of Two Models. Journal of Travel Research, 2631. 
Peter, J. P., \& Ryan, M. J. (1976). An Investigation of Perceived Risk at the Brand Level. Journal of Marketing Research, 13, 184-188.

Plog, S. (1994). Developing and Using Psychographics in Tourism Research. In J. R. B. Ritchie \& C. R. Goeldner (Eds.), Travel, Tourism, and hospitality Research: A Handbook for Managers and Researchers John Wiley \& Sons (2nd ed.).

Richter, L. K. (2003). International Tourism and Its Global Public Health Consequences. Journal of Travel Research, 41, 340-347.

Reisinger, Y., \& Mavondo, F. (2005). Travel Anxiety and Intentions to Travel Internationally: Implications of Travel Risk Perception. Journal of Travel Research, 43(3), 212-225.

Roehl, W. S., \& Fesenmaier, D. R. (1992). Risk Perceptions and Pleasure Travel: An Exploratory Analysis. Journal of Travel Research, 17-26.

Shin, H. C. (1998). The Hierarchical Effects of Perceived Constraining Attributes Influencing tourists' travel decision process. Unpublished Ph.D., The Pennsylvania State University.

Sonmez, S., \& Graefe, A. (1998a). Influence of Terrorism Risk on Foreign Tourism Decisions. Annals of Tourism Research, 25(1), 112-144.

Sonmez, S. F., \& Graefe, A. R. (1998a). Determining future travel behaviour from past travel experience and perceptions of risk and safety. Journal of Travel Research, 37(2), 171-178.

Stone, R. N., \& Gronhaug, K. (1993). Perceived Risk: Further Considerations for the Marketing Discipline. European Journal of Marketing, 27(3), 39-50. 